\title{
Schwannoma of the brachial plexus: a rare cause of monoparesis
}

\author{
Munna Lal Patel, ${ }^{1}$ Rekha Sachan, ${ }^{2}$ Ganesh Seth, ${ }^{3}$ Radheshyam ${ }^{4}$
}

${ }^{1}$ Department of Internal Medicine, CSM Medical University, Lucknow, Lucknow, Uttar Pradesh, India

${ }^{2}$ Department of Obstetrics \& Gynaecology, CSM Medical University, Lucknow, Lucknow, Uttar Pradesh, India

${ }^{3}$ Department of Medicine, KGMU, Lucknow, Uttar Pradesh, India ${ }^{4}$ Department of Critical Care, SGPGIMS, Lucknow, Uttar Pradesh, India

\section{Correspondence to} Dr Munna Lal Patel, apatelsac@gmail.com

\section{DESCRIPTION}

Schwannomas, also referred as neurilemmomas, are benign, encapsulated perineural tumour of neuroectdermal derivative that originate from the schwan cells of the neural sheath of motor and sensory peripheral nerves. About $25 \%$ of schwannomas occur in the head and neck region, ${ }^{1}$ usually

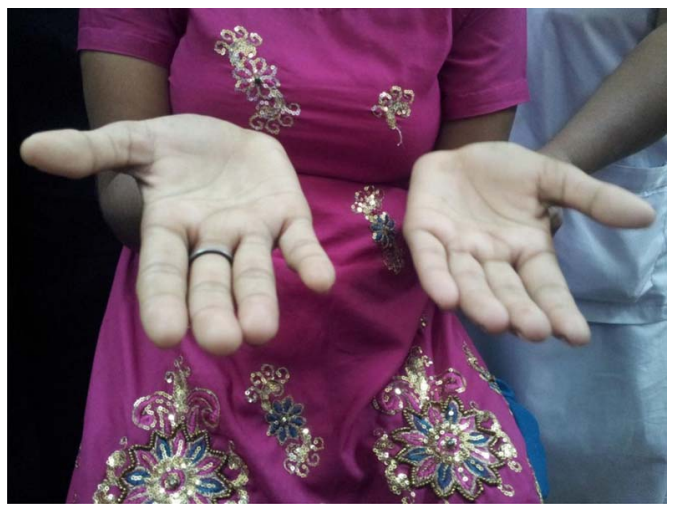

Figure 1 Wasting of thenar and hypothenar eminance. involving cranial nerves and sympathetic chain; however, brachial plexus schwannomas are uncommon, occurring in $0.3-0.4 / 100000$ person per year. $^{2-4}$ Their malignant potential is low, they can be locally destructive if allowed to progress. Primary tumours of the brachial plexus are unusual. Patients commonly seek medical attention

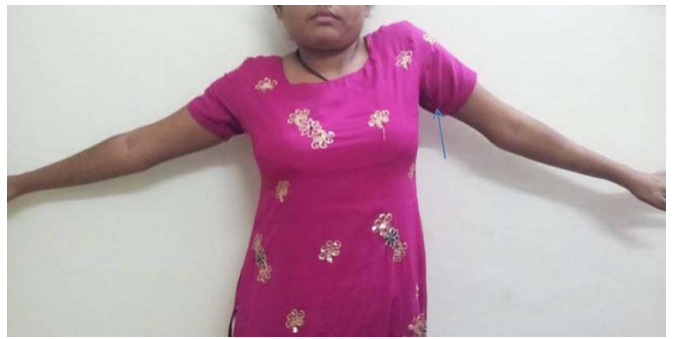

Figure 2 Patient is trying to do abduction of both shoulder: normal abduction on the right and poor on the left side. While trying to do shoulder abduction, the patient tilted on the right side to compensate the weakness of the left side.

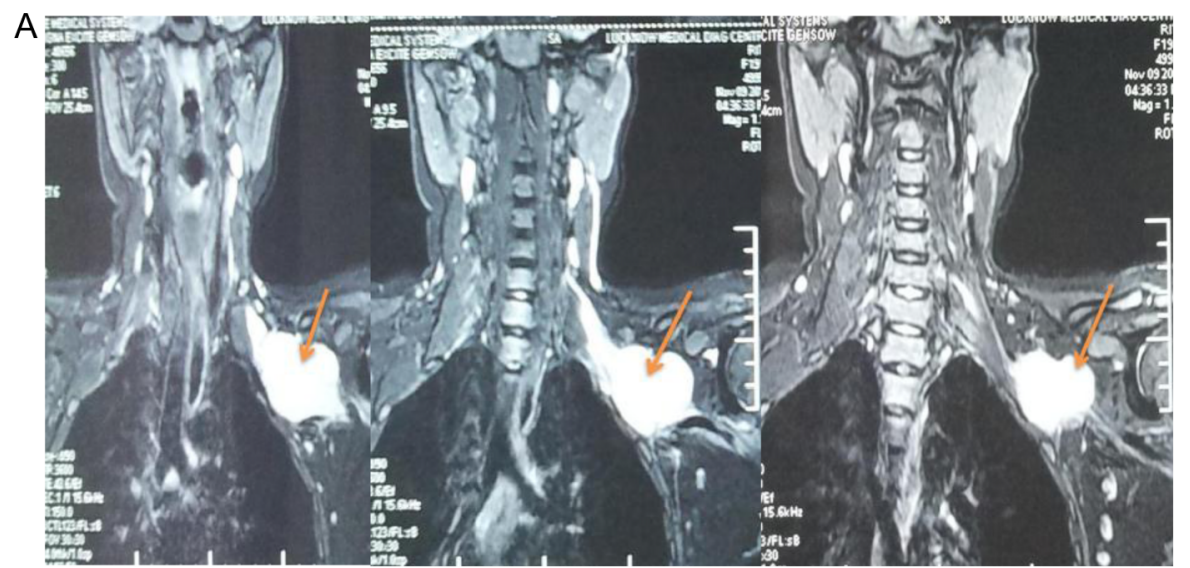

To cite: Patel ML, Sachan R, Seth $G$, et al. BMJ Case Rep Published online: [please include Day Month Year] doi:10.1136/ bcr-2012-008525

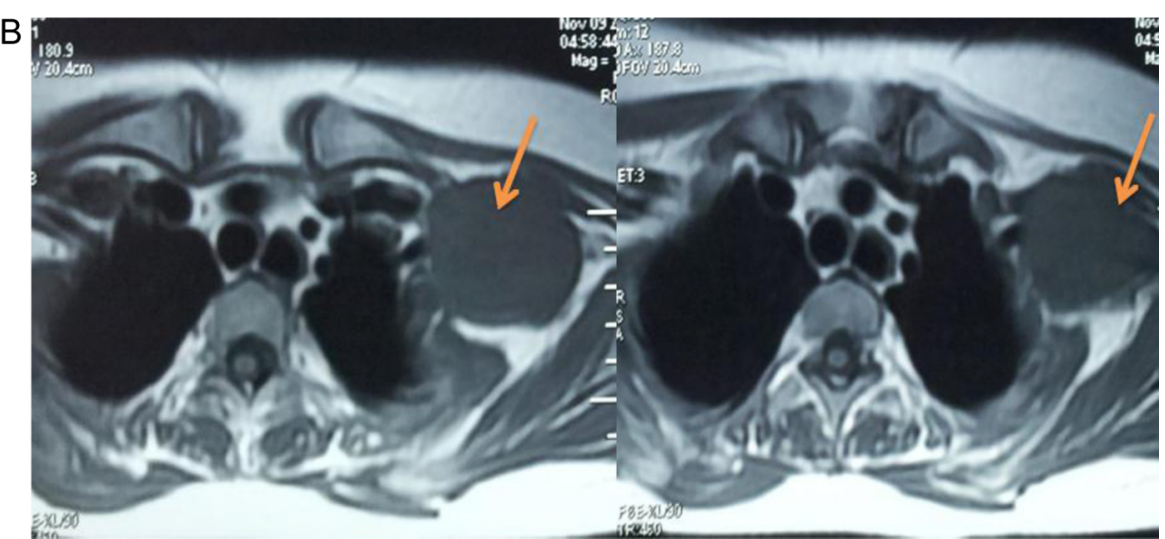

Figure 3 (A) MRI coronal T2 STIR sequence showing a well-defined cone-shaped hyperintense lesion in left axilla (thin yellow arrow).(B) MRI axial T1 sequence same lesion displaying hypointense signal (thick yellow arrow). 


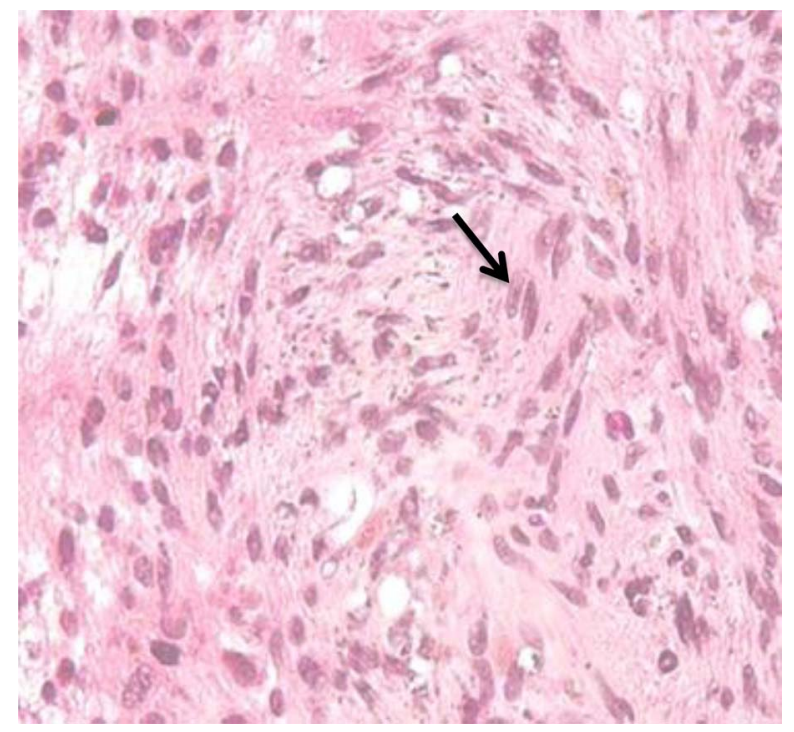

Figure 4 Histopathology showing spindle-shaped Schwann cells intermixed with foamy macrophages.

because of pain and loss of function of the affected part of the body. We report a case of schwannoma arising from left brachial plexus and presented as monoparesis of left upper limb.

A young 16-year-old girl presented to our hospital with sharp shooting pain on medial aspect left upper limb radiating up to medial aspect of hand since 10 months. Over the last 2 months, she noticed progressive weakness in left hand along with the inability to perform fine tasks (difficulty in gripping objects, breaking morsels). There was no history of trauma, fever, change in voice and weight loss.

Examination revealed normal vitals and no swelling, pigmentation (freckles or café-au-lait spots) or localised tenderness around left supra-clavicular region, axilla or anywhere in the body.

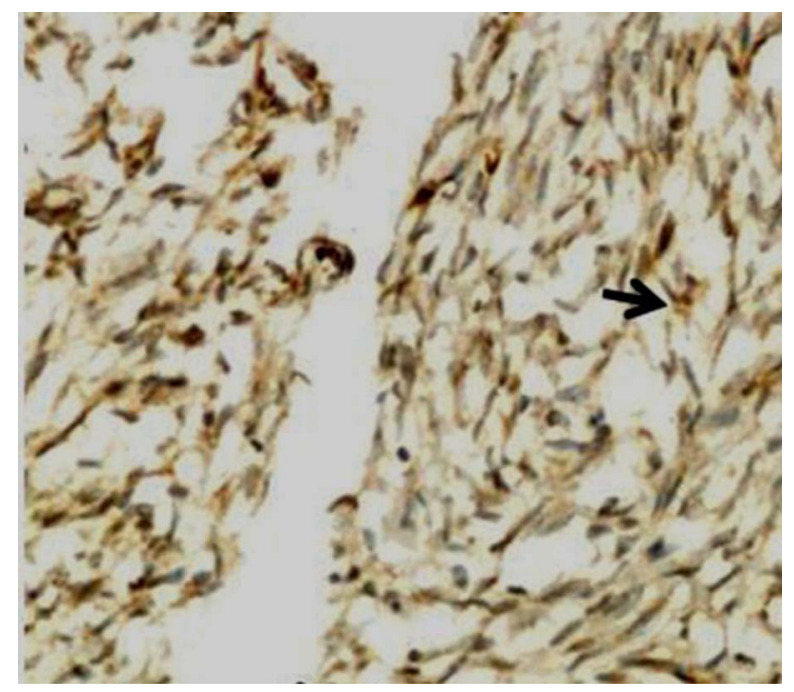

Figure 5 Immunohistochemistry shows $\mathrm{S} 100$ antigen positivity in tumour cells (immunostain $5100 \times 200$ ).
Neurological assessment showed normal higher mental functions and cranial nerve examination. Hypotonia was noted in the left upper limb along with wasting of biceps, triceps, deltoid, supraspinatus, infraspinatus and the intrinsic muscles of the hands. Weakness was noted in these muscles (distal involvement more than proximal) with grade 3 to 4 power as per medical research council grading. Sensory modalities for touch, temperature and pin prick were lost in left upper arm. Rest of the examination was normal (figures 1 and figures 2).

On investigation, complete blood count, random blood sugar, liver and kidney function tests were normal. $x$-Ray cervical spine and left shoulder region did not reveal any obvious bony abnormality. MRI coronal T2 STIR sequence reveals a well-defined cone-shaped hyperintense lesion in left axilla; it also reveals the narrow tapering medial part of the lesion approaching C7/D1 neural foramina along with its widening, suggesting nerve sheath tumour (figures 3A,B).

A core biopsy was obtained through CT guidance and the histological finding of the tissue revealed benign spindle cell neoplasm arranged in fascicles, intermixed with hypocellular and hypercellular areas. The hypercellular areas showed a palisading pattern with formation of Verocay bodies (small groups of fibrils surrounded by rows of palisaded nuclei), while the hypocellular area showed dispersed spindle cells in the myxoid stroma. Immuno histochemistry examination showed that the sample was S100 antigen-positive and desmin-negative suggestive of schwannoma (figures 4 and 5). The patient was examined by a neurosurgeon and complete excision of the tumour is being planned.

\section{Learning points}

Schwannoma may present as unrecognised slow-growing tumour.

- Benign classification underestimates their potential size and the damage they can cause to surrounding structures.

- Timely diagnosis and appropriate management may prevent such complications.

Acknowledgements We acknowledge the Department of Radiology, KGMU, Lucknow for images.

Competing interests None.

Patient consent Obtained.

Provenance and peer review Not commissioned; externally peer reviewed.

\section{REFERENCES}

1 Hui-Chi KU, Yeh C-W. Cervical Schwannoma. A case report \& eight years review. J Laryngol Otol 2000;114:414-17.

2 Kanatas A, Mucke T, Houghton D, et al. Schwannoma of the head and neck. Oncol Rev 2009;3:107-11.

3 Lusk MD, Kline DG, Garcia CA. Tumors of the brachial plexus. Neurosurgery 1987;21:439-53.

4 Ganju A, Roosen N, Kline DG, et al. Outcomes in a consecutive series of 111 surgically treated plexal tumors: a review of the experience at the Louisiana State University Health Sciences Center. J Neurosurgery 2001;95:51-60. 
Copyright 2013 BMJ Publishing Group. All rights reserved. For permission to reuse any of this content visit http://group.bmj.com/group/rights-licensing/permissions.

BMJ Case Report Fellows may re-use this article for personal use and teaching without any further permission.

Become a Fellow of BMJ Case Reports today and you can:

- Submit as many cases as you like

- Enjoy fast sympathetic peer review and rapid publication of accepted articles

- Access all the published articles

- Re-use any of the published material for personal use and teaching without further permission

For information on Institutional Fellowships contact consortiasales@bmjgroup.com

Visit casereports.bmj.com for more articles like this and to become a Fellow 